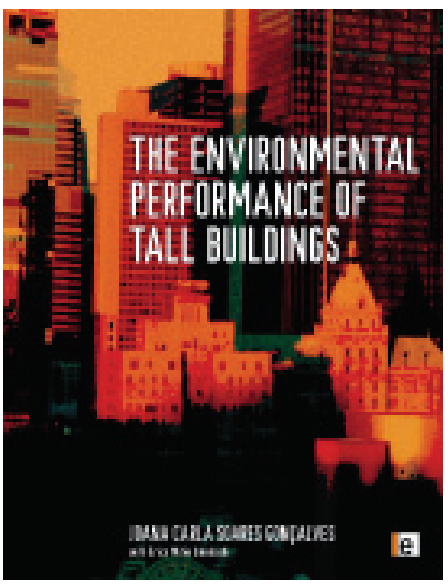

\section{THE ENVIRONMENTAL} PERFORMANCE OF TALL BUILDINGS

Gonçalves, Joana Carla Soares; umakoshi, Erica Mitie (Colaboração). São Paulo: Earthrcan, 2010,352 P. 246 Mm X I 89 MM.

ISBN: $978-\mathrm{I} 84-407-8$ I $2-7$

Roberta Consentino Kronka Mülfarth

O “VERDE” NAS ALTURAS: O DESEJO DA VERTICALIDADE E O PARADIGMA DA SUSTENTABILIDADE DO EDIFÍCIO ALTO NAS CIDADES

As discussões geradas pelo desejo da verticalidade ainda estão certamente longe de um consenso, fazendo com que questões relacionadas aos aspectos de adensamento, renovação urbana, desenvolvimento urbano, avanço tecnológico e aspectos inerentes à imagem do edifício alto façam parte desse universo ainda tão inexplorado. Somados a todos esses aspectos insere-se a "sustentabilidade" e o "baixo impacto ambiental" que, certamente, em muitos países, estão longe de serem condicionantes de projeto, mas ainda, na maioria dos casos, são elementos meramente de marketing, reflexo de interesses comerciais e políticos.

Como conseqüência natural dessa temática, surge a indagação: por que considerar um edifício alto sustentável e com baixo impacto ambiental? E é justamente explorando todas essas facetas, que a professora, arquiteta e pesquisadora Joana Carla Soares Gonçalves, em The environmental performance of tall building consegue expor e levar-nos a várias reflexões em uma instigante viagem relacionada ao desejo da verticalidade e ao paradigma da sustentabilidade do edifício alto nas cidades.

Como ponto de partida poderíamos apontar duas razões principais para considerar os edifícios altos com menor impacto ambiental e mais sustentáveis. Em primeiro lugar, o crescimento explosivo da população mundial nas últimas décadas, as previsões para as próximas décadas e a conseqüente pressão sobre os estoques de recursos do planeta têm sido fortes argumentos para edifícios altos e seu papel na sustentabilidade urbana. Ou seja, os centros urbanos, nos quais, na maioria das vezes, o edifício alto já é uma tipologia corriqueira, com áreas consolidadas e de maior densidade, passa a ser uma alternativa para ocupação.

Avaliando os aspectos urbanos dessa discussão, também se deve considerar que a relação entre a tipologia do edifício alto e densidade não é direta, da mesma forma que a densidade urbana não depende de edifícios altos, embora possa ser alcançada por meio dela. Além disso, as políticas voltadas para os 
edifícios altos e os critérios de projeto, olhando para o impacto sobre as condições do solo e do ambiente construído, precisam ser contextualizados para cumprir as metas de sustentabilidade.

Em segundo lugar, a construção de distritos financeiros ao redor do mundo, galgados em modelos comerciais europeus e norte-americanos, tem feito com que aspectos relacionados com a eficiência energética dessas tipologias, bem como o impacto ambiental das mesmas fiquem em um segundo plano em nome da tão almejada globalização. Assim, durante as últimas duas décadas, o mundo testemunhou cidades inteiras sendo transformadas em conjuntos de edifícios altos, mais notadamente no Oriente Médio e Ásia. As diferenças climáticas entre a localização dos distritos financeiros atuais e os dos modelos comerciais vigentes, apesar de serem gritantes, passam despercebidas, justificando até o fraco desempenho energético dos mesmos. Por esse motivo, o projeto do edifício alto comercial precisa ser criticamente revisado para ser capaz de cumprir as metas globais de desempenho energético.

No final da década de 1920 e nos anos 30 já é possível observar o edifício alto como uma tipologia importante no tecido urbano de Nova York e Chicago. Essa tipologia cresce em cidades da Europa após a Segunda Guerra Mundial e chega a algumas das grandes cidades da Ásia e do Oriente Médio, nas últimas décadas do século passado, trazendo alguns exemplos sem precedentes históricos.

Tendo como pano de fundo esse cenário, Joana Gonçalves expõe todas as questões relacionadas com o edifício alto, transitando desde aspectos históricos e conceituais até os aspectos tecnológicos dessa tão instigante tipologia. Logo no início, ao começar nossa jornada pela história da arquitetura e da cidade, é possível observar que a utopia e o projeto do edifício alto sempre estiveram presentes. O desejo pela verticalidade, somado ao seu inerente simbolismo, fizeram do edifício alto um "objeto de desejo" e de status. Transitando pelas utopias do século passado, a cidade moderna de Le Corbusier, Archigram, os metabolistas japoneses, entre outros, é possível identificar uma busca de solução para o urbanismo caótico de sua época e até mesmo a necessidade de construção de um novo marco para a cidade. Chegando aos dias atuais, em países como a China e Dubai, é possível constatar que a forma criativa e visionária de resolver os problemas, por meio das utopias, saiu do "mundo dos sonhos" e passou a ser imediatamente construída, resultado de pesquisas e de novas tecnologias desenvolvidas pela indústria.

Na cidade moderna, a inserção da tipologia do edifício alto também tem razões que vão além da busca do lucro máximo sobre o valor dos terrenos, e aquelas estão relacionadas ao interesse pela imagem inerente à verticalidade. Nessa cidade, além do desejo da verticalidade estar associado à realização de desafios tecnológicos, o edifício alto é uma resposta e uma conseqüência da evolução econômica e industrial. Durante décadas, os desafios inerentes à realização do edifício alto, incluindo a estrutura, a construção de sistemas e segurança contra incêndios, têm motivado arquitetos e engenheiros no desenvolvimento de projetos mais ambiciosos e na quebra de barreiras e limites de altura.

Além desses aspectos, Joana Gonçalves nos faz constatar, que, ao longo da história da arquitetura, o desejo pelo edifício alto extrapolou aspectos arquitetônicos, econômicos e até de políticas locais, tornando a "corrida pelo 
(1) Capítulos do livro: Capítulo 1: "The Tall Building and the City" (com participação de Rafael Silva Brandão, no subitem: The environmental impacts of single tall buildings upon the surroundings); Capítulo 2: "Global Perspective"; Capítulo 3: "Toward an Environmental Aproach" (com participação de Leonardo Marques Monteiro no subitem Thermal Confort in Buildings, e Mônica Pereira Marcondes no subitem: Climate as an architectural drive); Capítulo 4: "The Envirornmental Paradigm of Tall Building" Capítulo 5: "Final Considerations". edifício alto" uma competição de supremacia econômica entre cidades, corporações e até de nações.

Passando pelo nascimento da tipologia do edifício alto nos Estados Unidos, onde, pela primeira vez na história, foi utilizado o termo "arranha-céus" (Tribune Tower, 1925; Chrysler Building, 1930; Empire State Building, 1932) pelas propostas dos modernistas europeus, Mies van der Rohe e Le Corbusier; além dos edifícios altos utópicos, é possível avaliar como essa tipologia instigou propostas e até críticas acerca da cidade moderna e o modo pelo qual o homem se apropriou da mesma.

Com a crise energética dos anos 70, a inserção da variável "ambiental" acaba sendo uma conseqüência e aspectos relacionados com a luz e ventilação naturais passam a ser mais explorados, colocando, de certa forma, uma grande indagação na tipologia do edifício alto selado. Nas décadas seguintes, com as questões relacionadas ao desempenho ambiental na arquitetura, tendo atingido a agenda internacional (Brutland Report, oficialmente intitulado Nosso Futuro Comum, 1987, e a Agenda 21, 1993), as questões relacionadas com consumo de energia, impacto ambiental e sustentabilidade passaram a ser importantes requisitos não só no desenho dos edifícios, mas também no espaço urbano.

Além da disputa pelo edifício alto "mais alto", surgem os primeiros edifícios dentro da busca pelo menor impacto ambiental e maior sustentabilidade: Hong Kong e Shanghai Bank, em Hong Kong, e Commerzbank, em Frankfurt. Diante dessa nova perspectiva e possibilidades de utilização da iluminação e ventilação natural com grande eficiência, dentre outros mecanismos para a eficiência energética e diminuição dos impactos da edificação, inaugura-se, definitivamente, uma nova era dos edifícios de baixo impacto ambiental.

E, após ter iniciado nossa viagem pelos precedentes históricos e refletido sobre as condicionantes dessa instigante tipologia, Joana Gonçalves nos leva a entender quais são as variáveis que realmente levam a um desempenho ambiental favorável, dentro de um cenário de eficiência energética e sustentabilidade urbana e da edificação.

Dentro das perspectivas de cada país, são avaliados, em um contexto global, como a Europa, a América do Norte, do Sul e a Ásia respondem a essas novas demandas. Aspectos relacionados com o impacto do edifício alto são avaliados, tendo como suporte as questões relativas à densidade, forma e qualidade urbana, além das questões relacionadas com o microclima urbano (com considerações específicas relacionadas ao acesso solar e ventilação urbana). Também são avaliados aspectos de diretrizes de projeto relacionados ao clima e ao conforto térmico dessas edificações ${ }^{1}$.

Já tendo como base esses condicionantes ambientais, dentro dessa ótica, Joana Gonçalves nos faz "avaliar" importantes projetos aclamados mundialmente como "ambientalmente corretos": na Europa: Commerzbank Headquarters, 30 th Saint Mary Axe, 110 Bishopsgate (Heron Tower), 122 Leadenhall Street, 22-24 Bishopsgate Street (Pinnacle); na América do Norte: 4 Times Square, Hearst Tower, New York Times, Bank of America at One Brian Park; na América do Sul: Eldorado Business Tower, Ventura, Properitas; na Ásia: Aldar Central Market e Pearl River Tower.

E, no percurso dessa viagem, rumo às alturas, Joana Gonçalves faz algumas proposições de análise que nos faz constatar: nossa jornada ainda não chegou ao seu destino, e ainda existirá um grande mistério e várias indagações. 
Será que esses edifícios, realmente, atingiram uma performance tal a ponto de serem aclamados como "ambientalmente corretos" ou qualquer outro termo equivalente? Existe um consenso sobre o "ambientalmente correto"? Ou existe uma forte pressão pela imagem e um grande apelo de marketing em detrimento a um real desempenho?

Criou-se um falso paradigma desses edifícios que, em muitos casos, consomem muito mais energia que edifícios ditos "convencionais" em nome da utilização de "sofisticações tecnológicas"?

Seria, essa nova geração de edifícios, uma resposta à pressão ambiental mundial ou meramente resultado de um formalismo advindo de "modismo ambiental"?

Esses edifícios estariam respondendo às expectativas do século 21? E quais seriam esses desafios?

E é justamente na procura de respostas a essas indagações que se verifica que a jornada proposta por Joana Gonçalves apenas está em seu inicio, e, com certeza, terá de passar, exaustivamente, não só pelos aspectos ambientais, mas também sociais, tecnológicos e econômicos, baseados em uma profunda revisão do processo de projeto, não só dos edifícios, mas, principalmente, das cidades que iremos querer para abrigá-los.

\section{Roberta Consentino Kronka Mülfarth}

Arquiteta e urbanista pela FAUUSP, mestre em energia pelo Instituto de Eletrotécnica e Energia (IEE-USP) e doutora em Estruturas Ambientais Urbanas pela FAUUSP, na qual é docente. Atualmente, é também professora na Faculdade de Arquitetura e Urbanismo da Universidade Presbiteriana Mackenzie.

Rua do Lago, 876. Cidade Universitária 05508-900 - São Paulo, SP

(11) 3091-4571

aut@usp.br 